\title{
The Effects of Mung Bean Peptide and Its' Complexes on the Treatment of Lead Poisoning
}

\author{
Wei Wei, ${ }^{1,2}$ Shue Wang, ${ }^{3}$ Xue-Jun Zhang, ${ }^{2}$ Jiu-Xun Zhang, ${ }^{2}$ Zheng-Wang Chen, ${ }^{2}$ \\ Jia-Ying Huang, ${ }^{1}$ and Ye-Wang Zhang $\mathbb{D}^{1}$
}

${ }^{1}$ School of Pharmacy, Jiangsu University, Zhenjiang 212013, China

${ }^{2}$ Shandong Tianjiu Industry Group, Heze 274108, China

${ }^{3}$ School of Public Health, Shandong University, Jinan 250012, China

Correspondence should be addressed to Ye-Wang Zhang; zhangyewang@ujs.edu.cn

Received 20 April 2021; Accepted 19 July 2021; Published 23 July 2021

Academic Editor: Fuguo Liu

Copyright (c) 2021 Wei Wei et al. This is an open access article distributed under the Creative Commons Attribution License, which permits unrestricted use, distribution, and reproduction in any medium, provided the original work is properly cited.

Objective. To investigate the effects of mung bean peptide and its' complexes on promoting lead excretion and neuroprotection of zebrafish. Methods. The lead poisoning models of zebrafish were established by lead acetate solution; the models were treated with high and low concentrations ( 58.3 and $175 \mu \mathrm{g} / \mathrm{mL}$ ) of mung bean peptides, with high, medium, and low concentrations $(27.8,83.3$, and $250 \mu \mathrm{g} / \mathrm{mL}$ ) of mung bean peptide complexes, separately. The effects of the mung bean peptide complexes on the lead content, axonal fluorescence intensity, and peripheral motor nerve length changes were identified in the zebrafish model, and the effects of mung bean peptide and its' complexes on zebrafish's lead excretion, axonal protection rate, and peripheral movement promotion rate of nerve regeneration were calculated. Results. The effects of high concentration of mung bean peptide $(175 \mu \mathrm{g} / \mathrm{mL})$ in promoting lead excretion was $29 \%(p<0.05)$, and the effect of high concentration of mung bean peptide complexes $(250 \mu \mathrm{g} / \mathrm{mL})$ in promoting lead excretion was 30\% $(p<0.05)$. The other concentrations of mung bean peptide and its' complex groups did not show a noticeable lead excretion effect. The protective effects of mung bean peptide at concentrations of 58.3 and $175 \mu \mathrm{g} / \mathrm{mL}$ against zebrafish axonal injury were $98 \%$ and $101 \%(p<0.01)$, and the peripheral nerve regeneration promotion effects were $29 \%$ $(p>0.05)$ and $42 \%(p<0.05)$, respectively. The protective effects of mung bean peptide complexes at concentrations of 27.8, 83.3, and $250 \mu \mathrm{g} / \mathrm{mL}$ against zebrafish axonal injury were $85 \%, 78 \%$, and $93 \%(p<0.01)$; peripheral nerve regeneration promotion rates were $46 \%, 50 \%$, and 50\% ( $p<0.05)$. Conclusion. The mung bean peptide and its' complexes can effectively promote the discharge of lead in the zebrafish lead poisoning and have protective and regeneration effects on zebrafish nerves.

\section{Introduction}

Lead $(\mathrm{Pb})$ is a common neurotoxic heavy metal pollutant, which is widely used in industrial activities, and enters the environment through different routes $[1,2]$. Acute lead exposure can cause neurotoxic effects in animals, such as abnormal behavior, learning disabilities, and hearing loss [3]. In addition to its apparent neurodevelopmental toxicity, lead can also destroy the redox state of the body by directly inducing the body to produce reactive oxygen species and consuming intracellular antioxidants, leading to oxidative damage to the body, which would cause injuries to tissues and organs, especially in the nervous system $[4,5]$.
Lead can easily pass through the blood-brain barrier, inhibiting the development of the central nervous system [6]. The normal development of glial cells has an important influence on the migration of neurons and the establishment of synaptic connections. Lead can also lead to the premature differentiation of glial cells, and the interactions between glial cells and neurons cannot proceed normally [7]. Besides, lead can accumulate in endothelial cells, and it can also affect the formation of synapses through calcium-like effects and nerve cell adhesion molecules [8].

Mung beans are rich in protein, starch, minerals, vitamins, and essential amino acids, among which the protein content is $19.5 \%$ to $33.1 \%[9,10]$. In the past 20 years, researchers have found that the peptides from food-derived proteins have a wide 
range of biologically active functions, such as antioxidation, lowering blood pressure, lowering cholesterol, and improving the body's immunity [11-17]. In recent years, more and more attention has been paid to the studies on the health mechanism of mung bean peptides (MBPs), especially the neuroprotective mechanism. However, there is no report on repairing nerve injury caused by lead poisoning with MBPs [16].

Zebrafish has the characteristics of small size, short reproduction cycle, rapid embryo development, transparent embryo body, and high homology with mammals [18]. The effects of complexes on the nervous system in live or intact fixed specimens through special staining can be quickly detected. Organic damage is a model activity widely used in developmental toxicology, genetic biology, drug development, and environmental monitoring [19-22]. In order to further explore the effects of mung bean peptides and mung bean peptide complexes in promoting lead excretion and protecting nerves, a zebrafish lead poisoning model through induction was established, and the effects of different concentrations of mung bean peptide and mung bean peptide complexes on zebrafish in promoting lead excretion and neuroprotection were observed.

\section{Materials and Methods}

2.1. Drugs and Main Reagents. Mung bean peptide and mung bean peptide complexes were supplied from Zhongshiduqing (Shandong) Biological Co., Ltd. (Heze, China); calcium sodium edetate was purchased from Huazhong Haiwei Gene Technology Co., Ltd. (Beijing, China); lead acetate trihydrate and other reagents were provided by Shanghai Aladdin Biochemical Technology Co., Ltd. (Shanghai, China).

2.2. Main Instruments. Dissecting microscope (SZX7, OLYMPUS, Japan); precision electronic balance (CP214, OHAUS, China); inductively coupled plasma mass spectrometer (thermoelectric, XII type, Thermo); motorized focusing continuous zoom fluorescence microscope (AZ100, Nikon, Japan); antimicrotubule and related protein antibodies (T6793, Sigma, USA); 6-well plate (Nest, China); methylcellulose (Sigma, China).

2.3. Animals. The wild-type $A B$ strain of zebrafish was reproduced by natural paired mating. A total of 2130 fishes with an age of $2 \mathrm{hpf}$ were used to determine the maximum tolerated concentration (MTC) of mung bean peptide complexes, evaluate the lead excretion effects of mung bean peptide and mung bean peptide complexes, and evaluate the protective effects of injured axonal. Motor neuron fluorescent zebrafish (NBT strain) was reproduced by natural paired mating. A total of 240 fishes, with an age of $2 \mathrm{hpf}$, were used to evaluate the effect of mung bean peptide and mung bean peptide complexes on the promotion of peripheral motor nerve regeneration. The above zebrafish were raised in fish farming water at $28^{\circ} \mathrm{C}$ (water quality: $200 \mathrm{mg}$ of instant sea salt was added to each $1 \mathrm{~L}$ of reverse osmosis water, conductivity was $480 \sim 510 \mu \mathrm{S} / \mathrm{cm}$; $\mathrm{pH}$ is 6.9 7.2; hardness was $53.7 \sim 71.6 \mathrm{mg} / \mathrm{L} \mathrm{CaCO}_{3}$ ).

2.4. Determination of Mung Bean Peptide Complexes MTC. $2102 \mathrm{hpf}$ wild-type $A B$ strains of zebrafish were randomly selected in a six-well plate (30 fish per well, each well with a capacity of $3 \mathrm{~mL}$ ), and the mung bean peptide complexes $(50,100,250,500$, and $1000 \mu \mathrm{g} / \mathrm{mL})$ were dissolved in water to obtain different concentrations. A normal control group (zebrafish treated with water for fish farming) and model control group were set up. The dead zebrafish were observed and removed every day. After the mung bean peptide complexes were treated to $72 \mathrm{hpf}$, the number of deaths of the zebrafish was counted, and the MTC of the zebrafish was determined according to the toxicity and death of the zebrafish.

\subsection{Evaluation of the Effects of Mung Bean Peptide and Mung} Bean Peptide Complexes in Promoting Lead Excretion. A total of 240 wild-type $A B$ strains of zebrafish were randomly chosen 2 hours ( 2 hpf) after fertilization and placed in a sixwell plate. There were 30 fish in each well with a capacity of $3 \mathrm{~mL}$ each, and a total of 6 parallel groups were treated. The models were treated with mung bean peptide $(58.3$ and $175 \mu \mathrm{g} / \mathrm{mL})$ and mung bean peptide complexes $(27.8,83.3$, and $250 \mu \mathrm{g} / \mathrm{mL}$ ) in water solution separately, and the positive control drug was injected with calcium sodium edetate $125 \mathrm{ng}$ per fish. Lead acetate was added to water to establish a lead poisoning model. After 70 hours, samples of zebrafish were collected by washing the liquid and sucking up the water for fish farming with EP tubes. Every 60 zebrafishes were set as a series of samples, and each of them was detected by ICP-MS. The lead content (C) of a zebrafish sample was converted to the ratio of total lead to the wet weight of the zebrafish, and $\mathrm{C}$ of the mung bean peptide and mung bean peptide complexes were used to evaluate the lead excretion effects of the complexes. The calculation formula for the lead excretion effect is as follows:

$$
\text { promoting lead discharge rate }(\%)=\frac{\mathrm{C}(\text { model control group })-\mathrm{C}(\text { test group })}{\mathrm{C}(\text { model control group })} \times 100 \% \text {. }
$$

2.6. Protective Effect on Axonal Injury. $2402 \mathrm{hpf}$ transgenic wild-type $A B$ strains of zebrafish were randomly chosen in a six-well plate (30 fish in each well, and each with a volume of
$3 \mathrm{~mL})$. The models were treated with mung bean peptide (58.3 and $175 \mu \mathrm{g} / \mathrm{mL}$ ) and mung bean peptide complexes $(27.8,83.3$, and $250 \mu \mathrm{g} / \mathrm{mL})$. After 70 hours of 
administration, the axonal-specific antibodies were stained, and the pictures were taken under a fluorescence microscope. Zebrafish head axonal fluorescence intensity (S) was collected to evaluate the axonal protection of the mung bean peptide and its' complexes. The formula for calculating the protective effect of axonal damage is as follows:

$$
\text { axonal protection rate }(\%)=\frac{S(\text { test group })-S(\text { model control group })}{S(\text { normal control group })-S(\text { model control group })} \times 100 \% \text {. }
$$

2.7. Promoting Regeneration of Peripheral Motor Neuron Injury. After 70 hours, pictures were taken under a fluorescence microscope to collect the average length of peripheral motor nerves $(\mathrm{L})$. The motor nerve length was used to evaluate the motor nerve regeneration effect of mung bean peptide and its' complexes. The formula for the promotion of regeneration of motor nerve injury is as follows:

$$
\text { motor nerve regeneration rate }(\%)=\frac{\mathrm{L}(\text { test group })-\mathrm{L}(\text { model control group })}{\mathrm{L}(\text { normal control group })-\mathrm{L}(\text { model control group })} \times 100 \%
$$

2.8. Statistical Analysis. The data were expressed as $(\bar{x} \pm s)$, and the differences were tested among the groups by $T$-test.

\section{Results and Discussion}

3.1. Determination of the MTC of Mung Bean Peptide Complexes. The mung bean peptide complexes induced $100 \%$ death of zebrafish at the concentrations of $500 \mu \mathrm{g} \mathrm{mL}^{-1}$ and above, and no apparent toxic phenotype was found at the concentrations of $250 \mu \mathrm{g} \mathrm{mL}^{-1}$ and below. Therefore, the MTC of mung bean peptide complexes is determined to be $250 \mu \mathrm{g} \mathrm{mL}^{-1}$ (Table 1). The concentration of mung bean peptide complexes was reduced to MTC, and $27.8 \mu \mathrm{g} \mathrm{mL}^{-1}$ (1/9 MTC), $\quad 83.3 \mu \mathrm{g} \mathrm{mL}^{-1} \quad(1 / 3 \quad$ MTC), and $250 \mu \mathrm{g} \mathrm{mL}^{-1}$ (MTC) were selected in the pharmacodynamic evaluation experiment. The mung bean peptide complexes contain $70 \%$ mung bean peptides. Therefore, the concentrations of the mung bean peptides in the regeneration test of peripheral motor nerve were set at $58.3 \mu \mathrm{g} \mathrm{mL}^{-1}$ (1/3 MTC) and $175 \mu \mathrm{g} \mathrm{mL}^{-1}$ (MTC), respectively.

3.2. Lead Excretion Effect of Mung Bean Peptide and Its' Complexes. After successfully establishing zebrafish lead poisoning models, they were treated with mung bean peptide and its' complexes, respectively. After 70 hours, the zebrafish samples were collected by washing the liquid and sucking up the water for fish farming with EP tubes. Three parallel samples were tested for each experimental group, and each 60 zebrafish was considered as one sample. The lead content of zebrafish in the lead poisoning model control group $\left(9.01 \mu \mathrm{g} \mathrm{g}^{-1}\right)$ was significantly higher than that of the normal control group $\left(3.11 \mu \mathrm{gg}^{-1}\right)$, indicating that the model was successfully constructed $(p<0.01)$. The positive control group (calcium sodium edetate $125 \mathrm{ng}$ per fish) contained $8.38 \mu \mathrm{g} \mathrm{g}^{-1}$ of lead, and the effect of promoting lead excretion was $7 \%$, indicating that calcium sodium edetate has a certain tendency to promote lead excretion under the experimental dose conditions.
Compared with the model control group, the lead content of the zebrafish in the mung bean peptide high concentration group $(175 \mu \mathrm{g} / \mathrm{mL})$ was significantly reduced $(p<0.05)$, and the lead excretion effect was $29 \%$; compared with the model control group, the lead content of the zebrafish in the mung bean peptide complexes high concentration group $(250 \mu \mathrm{g} / \mathrm{mL})$ was significantly reduced $(p<0.05)$, and the lead excretion effect was $30 \%$. There was no noticeable lead excretion effect in the other concentrations of mung bean peptide and mung bean peptide complexes, which shows that the appropriate concentration of mung bean peptide and mung bean peptide complexes have significant effects of promoting lead excretion (Table 2).

3.3. Mung Bean Peptide and Its' Complexes Protect the Injured Axonal. Compared with model group, calcium sodium edetate had a protective rate of $85 \%$ against zebrafish axonal injury $(p<0.05)$, mung bean peptide with the concentrations of 58.3 and $175 \mu \mathrm{g} / \mathrm{mL}$ had a protective effect on zebrafish, and the protection rates of axonal injury were $98 \%$ $(p<0.01)$ and $101 \%(p<0.01)$. Compared with the model group, the mung bean peptide complexes with the concentrations of $27.8,83.3$, and $250 \mu \mathrm{g} / \mathrm{mL}$ protected the injured axonal in zebrafish, and the rates were $85 \%(p<0.01)$, $78 \%(p<0.01)$ and $93 \%(p<0.01)$. The results showed that the appropriate concentration of mung bean peptide and mung bean peptide complexes had noticeable protective effects on zebrafish injured axonal (Figure 1 and Table 3).

3.4. The Protection of Mung Bean Peptide and Its' Complexes Promoting the Regeneration of Injured Peripheral Motor Neuron. Compared with the model group, calcium sodium edetate promoted the regeneration of zebrafish peripheral nerves by $46 \%(p<0.05)$. Compared with the model group, the mung bean peptide with the concentrations of 58.3 and $175 \mu \mathrm{g} / \mathrm{mL}$ had effects on the regeneration of peripheral nerve in zebrafish, and the regeneration rates were $29 \%$ $(p>0.05)$ and $42 \%(p<0.05)$. Compared with the model 
TABLE 1: The relationship of between the concentration of mung bean peptide complexes and the toxicity $(n=30)$.

\begin{tabular}{lcccc}
\hline Group & Concentration $\left(\mu \mathrm{g} \mathrm{m}^{-1}\right)$ & Number of deaths & Mortality rate (\%) & Toxic phenotype \\
\hline Normal control group & - & 0 & 0 & No obvious abnormalities \\
Model control group & - & 0 & 0 & 1 body bending \\
& 50 & 0 & 0 & No obvious abnormalities \\
Mung bean peptide complexes & 100 & 0 & 0 & 1 body bending and slowed heart rate \\
& 250 & 0 & 0 & 1 pericardium and renal edema \\
& 500 & 30 & 100 & - \\
\hline
\end{tabular}

TABle 2: The effects of mung bean peptide and mung bean peptide complexes on lead-removing in zebrafish.

\begin{tabular}{lccc}
\hline Group & Concentration $(\mu \mathrm{g} / \mathrm{mL})$ & Lead content $(\mu \mathrm{g} / \mathrm{g}$, mean $\pm \mathrm{SE})$ & Promoting lead discharge rate $(\%)$ \\
\hline Normal control group & - & $3.11 \pm 0.32$ & - \\
Model control group & - & $9.01 \pm 0.64^{*}$ & - \\
Calcium edetate & $125 \mathrm{ng}$ per fish & $8.38 \pm 0.27$ & 7 \\
Mung bean peptide & 58.3 & $8.28 \pm 1.17$ & 8 \\
& 175 & $6.43 \pm 0.11^{*}$ & 29 \\
Mung bean peptide complexes & 27.8 & $9.26 \pm 0.78$ & -3 \\
& 83.3 & $9.34 \pm 0.97$ & -4 \\
\hline
\end{tabular}

Note: compared with the normal control group, ${ }^{\#} p<0.01$; compared with the model control group, ${ }^{*} p<0.05$.

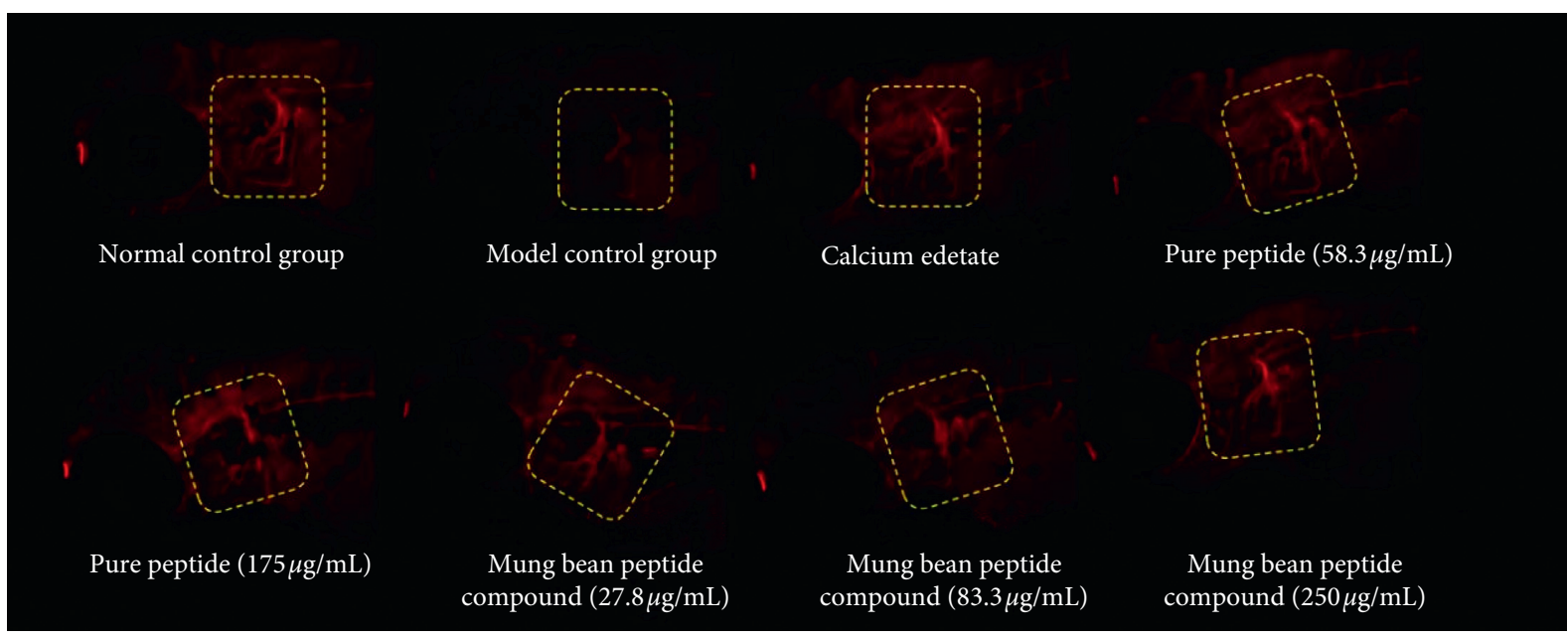

FIgURE 1: Phenotype diagram of the protective effect of mung bean peptide and mung bean peptide complexes on the axonal injury.

TABle 3: Protective effects of mung bean peptide and its' complexes peptides on zebrafish injured axonal $(n=10)$.

\begin{tabular}{lccc}
\hline Group & Concentration $(\mu \mathrm{g} / \mathrm{mL})$ & Axonal fluorescence intensity (pixel, mean \pm SE) & Axonal protection rate $(\%)$ \\
\hline Normal control group & - & $832327 \pm 18094$ & - \\
Model control group & - & $707955 \pm 23086$ & - \\
Calcium edetate & 125 ng per fish & $813117 \pm 31637^{*}$ & 85 \\
Mung bean peptide & 58.3 & $829757 \pm 23552 * *$ & 98 \\
& 175 & $833368 \pm 26475^{* *}$ & 101 \\
Mung bean peptide complexes & 27.8 & $814069 \pm 24781^{* *}$ & 85 \\
& 83.3 & $805023 \pm 19766^{* *}$ & 78 \\
\hline
\end{tabular}

Note: compared with the model control group, ${ }^{*} p<0.05,{ }^{* *} p<0.01$, and ${ }^{* * *} p<0.001$.

group, mung bean peptide complexes with the concentrations of $27.8,83.3$, and $250 \mu \mathrm{g} / \mathrm{mL}$ promoted the peripheral nerve regeneration, and the rates were $46 \%$ $(p<0.05), 50 \%(p<0.05)$, and 50\% $(p<0.05)$. The results indicated that the appropriate concentrations of mung bean peptide and mung bean peptide complexes could significantly promote the regeneration of peripheral nerves in zebrafish (Figure 2 and Table 4). 


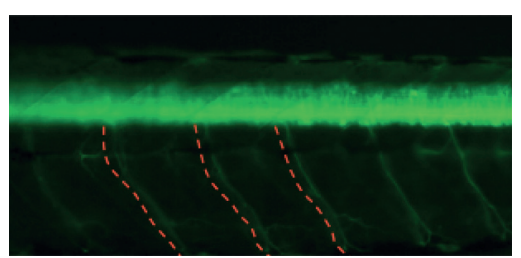

Normal control group

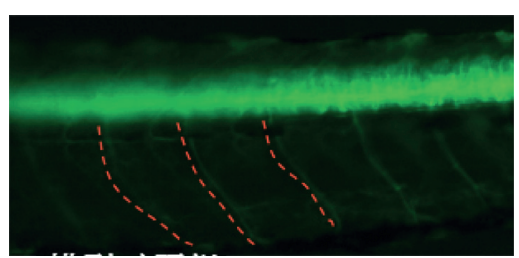

Model control group

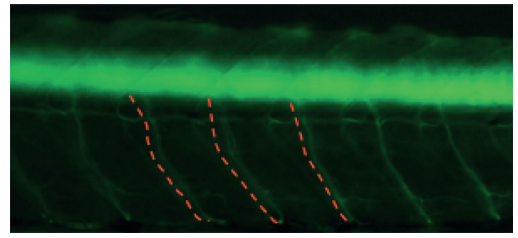

Calcium edetate

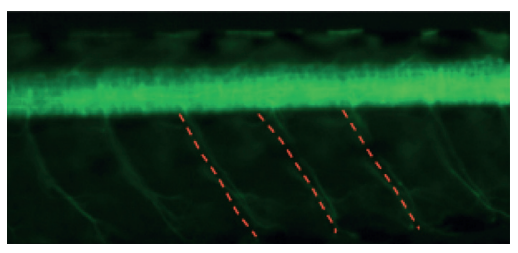

Mung bean peptide compound $(27.8 \mu \mathrm{g} / \mathrm{mL})$

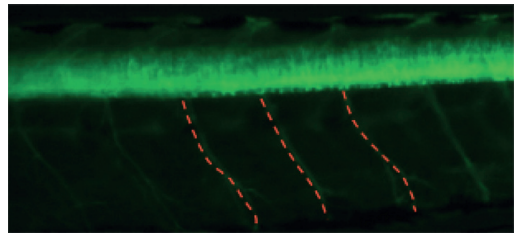

Pure peptide $(58.3 \mu \mathrm{g} / \mathrm{mL})$

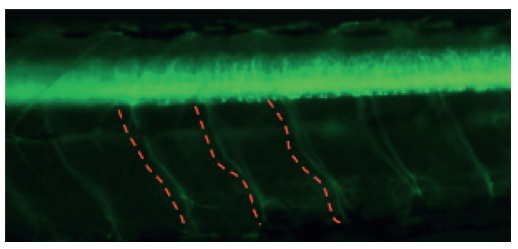

Mung bean peptide compound $(83.3 \mu \mathrm{g} / \mathrm{mL})$

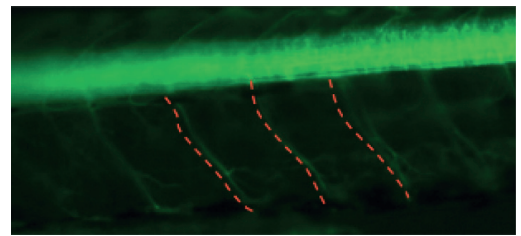

Pure peptide $(175 \mu \mathrm{g} / \mathrm{mL})$

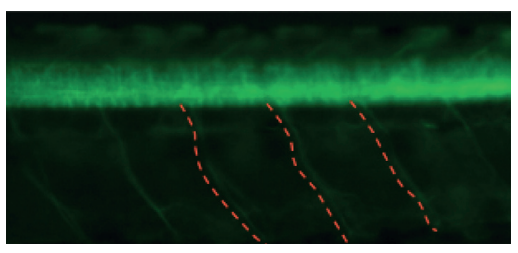

Mung bean peptide compound $(250 \mu \mathrm{g} / \mathrm{mL})$

Figure 2: Phenotype diagram of the promoting effect of mung bean peptide and mung bean peptide complexes on peripheral motor nerve regeneration.

TABle 4: The regenerative effects of mung bean peptide and its complexes on the injured peripheral motor nerve $(n=10)$.

\begin{tabular}{lccc}
\hline Group & $\begin{array}{c}\text { Concentration }(\mu \mathrm{g} / \\
\mathrm{mL})\end{array}$ & $\begin{array}{c}\text { Peripheral motor nerve length (pixel, } \\
\text { mean } \pm \text { SE) }\end{array}$ & $\begin{array}{c}\text { Promoting regeneration rate } \\
(\%)\end{array}$ \\
\hline Normal control group & - & $228 \pm 2.39$ & - \\
Model control group & - & $204 \pm 2.59$ & - \\
Calcium edetate & 125 ng per fish & $215 \pm 4.00^{*}$ & 46 \\
Mung bean peptide & 58.3 & $211 \pm 5.50$ & 29 \\
& 175 & $214 \pm 2.67^{*}$ & 42 \\
Mung bean peptide & 27.8 & $215 \pm 3.55^{*}$ & 46 \\
complexes & 83.3 & $216 \pm 3.61^{*}$ & 50 \\
\end{tabular}

Note: compared with the model control group, ${ }^{*} p<0.05$.

\section{Conclusion}

Lead is harmful to multiple systems and organs in the human body, including bone marrow, hematopoietic system, immune system, nervous system, digestive system, kidney, and heart $[22,23]$. With the development of industrialization and transportation in recent years, environmental lead pollution was increased, and the impact on human health has become increasingly severe [24]. Clinically, the treatment of lead poisoning mainly uses edetate calcium disodium and penicillamine, but these drugs have many side-effect reactions, such as kidney damage and allergic reactions [25]. Natural products have significant effects on the discharge of lead [26-28]. It has been reported that alliin in garlic can bind with lead to reduce the toxicity of lead-poisoned rats; konjac powder can specifically bind to lead and promote its discharge without affecting absorbing calcium, iron, and zinc, so the refined konjac powder can be used as a health food for preventing and controlling lead poisoning $[29,30]$.

Mung bean is recognized as a safe and nontoxic health food, which has attracted wide attention from all over the world [31]. At present, most focuses of mung bean is the processing of mung bean starch and vermicelli, ignoring the development and utilization of its byproduct mung bean protein $[32,33]$. Under the investigated concentration range of this work, the mung bean peptide and its' complexes provided by Zhongshiduqing (Shandong) Biological Co., Ltd. have significant effects on the excretion of lead, have a significant regenerative effect on zebrafish peripheral motor nerve damage caused by lead poisoning, and have an apparent protective effect on axonal injury.

After nerve injury, the neuron cell bodies cannot be regenerated, and the leading related functions will also be constantly under attack [34-37]. At present, the so-called nerve regeneration refers to the regeneration of axons, 
including axon growth, axon extension, rebuilding synaptic connections with target cells, realizing nerve reinnervation, and restoring function [38, 39]. Under normal circumstances, after peripheral nerve injury, Wallerian degeneration occurs at the proximal end of some nerves and all distal ends, which leads to degeneration and necrosis of nerve fibers and myelin sheaths to make nerve function disorders $[40,41]$. In this work, it was found that high-concentration mung bean peptide complexes $(250 \mu \mathrm{g} / \mathrm{mL})$ have a protection rate of $93 \%$ against zebrafish axonal damage and a 50\% promotion rate of peripheral neuron injury, indicating that mung bean peptide can protect zebrafish axonal and promote the regeneration of the peripheral motor nerve.

As a kind of agricultural product, mung bean is easy to grow, and the output of mung bean is very high. It is expected to develop mung bean peptide complexes as a leadpromoting health functional food, which would provide an adequate, nontoxic, green lead-emission health food for patients with chronic lead poisoning.

\section{Data Availability}

The data used to support the findings of this study are available from the corresponding author upon request.

\section{Conflicts of Interest}

The authors declare that they have no conflicts of interest.

\section{Authors' Contributions}

Wei Wei and Shue Wang contributed equally to this work.

\section{References}

[1] J.-W. Lee, H. Choi, U.-K. Hwang et al., "Toxic effects of lead exposure on bioaccumulation, oxidative stress, neurotoxicity, and immune responses in fish: a review," Environmental Toxicology and Pharmacology, vol. 68, pp. 101-108, 2019.

[2] J. G. Dórea, "Environmental exposure to low-level lead (Pb) co-occurring with other neurotoxicants in early life and neurodevelopment of children," Environmental Research, vol. 177, Article ID 108641, 2019.

[3] C. Sun, W. Li, Y. Liu et al., "In vitro/in vivo hepatoprotective properties of 1-O-(4-hydroxymethylphenyl)- $\alpha$-L-rhamnopyranoside from Moringa oleifera seeds against carbon tetrachloride-induced hepatic injury," Food and Chemical Toxicology, vol. 131, Article ID 110531, 2019.

[4] T. Vlasak, G. Jordakieva, T. Gnambs et al., "Blood lead levels and cognitive functioning: a meta-analysis," Science of the Total Environment, vol. 668, pp. 678-684, 2019.

[5] Y. He, L. Zou, W. Luo et al., "Heavy metal exposure, oxidative stress and semen quality: exploring associations and mediation effects in reproductive-aged men," Chemosphere, vol. 244, Article ID 125498, 2020.

[6] Y. Ge, L. Chen, X. Sun et al., "Lead-induced changes of cytoskeletal protein is involved in the pathological basis in mice brain," Environmental Science and Pollution Research International, vol. 25, pp. 11746-11753, 2018.

[7] J. Zhang, C. Yan, S. Wang et al., "Chrysophanol attenuates lead exposure-induced injury to hippocampal neurons in neonatal mice," Neural Regeneration Research, vol. 9, pp. 924-930, 2014.

[8] T. F. Pedroso, C. S. Oliveira, M. M. Fonseca et al., "Effects of zinc and $\mathrm{N}$-acetylcysteine in damage caused by lead exposure in young rats," Biological Trace Element Research, vol. 180, pp. 275-284, 2017.

[9] D. Hou, L. Yousaf, Y. Xue et al., "Mung bean (Vigna radiata L.): bioactive polyphenols, polysaccharides, peptides, and health benefits," Nutrients, vol. 11, no. 6, p. 1238, 2019.

[10] Z. Yi-Shen, S. Shuai, and R. FitzGerald, "Mung bean proteins and peptides: nutritional, functional and bioactive properties," Food \& Nutrition Research, vol. 62, p. 1290, 2018.

[11] A. Musa, M. A. A. Gasmalla, H. Ma et al., "A new continuous system of enzymatic hydrolysis coupled with membrane separation for isolation of peptides with angiotensin I converting enzyme inhibitory capacity from defatted corn germ protein," Food \& Function, vol. 11, pp. 1146-1154, 2020.

[12] A. Wali, H. Ma, R. M. Aadil, C. Zhou, M. T. Rashid, and X. Liu, "Effects of multifrequency ultrasound pretreatment on the enzymolysis, ACE inhibitory activity, and the structure characterization of rapeseed protein," Journal of Food Processing and Preservation, vol. 41, no. 6, Article ID e13413, 2017.

[13] A. P. A. Nwakiban, A. J. Sokeng, M. Dell'Agli et al., "Hydroethanolic plant extracts from Cameroon positively modulate enzymes relevant to carbohydrate/lipid digestion and cardio-metabolic diseases," Food \& Function, vol. 10, pp. 6533-6542, 2019.

[14] W.-S. He, H. Zhu, and Z.-Y. Chen, "Plant Sterols: chemical and enzymatic structural modifications and effects on their cholesterol-lowering activity," Journal of Agricultural and Food Chemistry, vol. 66, pp. 3047-3062, 2018.

[15] S. Chunkao, W. Youravong, C. T. Yupanqui et al., "Structure and function of mung bean protein-derived iron-binding antioxidant peptides," Foods, vol. 9, p. 1406, 2020.

[16] J. Kusumah, L. M. Real Hernandez, and E. Gonzalez de Mejia, "Antioxidant potential of mung bean (vigna radiata) albumin peptides produced by enzymatic hydrolysis analyzed by biochemical and in silico methods," Foods, vol. 9, no. 9, p. 1241, 2020.

[17] H. Qiu, L. Zhang, M. Zhu et al., "Capture of anti-coagulant active ingredients from Moutan Cortex by platelet immobilized chromatography and evaluation of anticoagulant activity in rats," Biomedicine \& Pharmacotherapy, vol. 95, pp. 235244, 2017.

[18] L. E. Swenarchuk, "Nerve, muscle, and synaptogenesis," Cells, vol. 8, p. 1448, 2019.

[19] J. A. Koenig, C. Acon Chen, and T.-M. Shih, "Development of a larval zebrafish model for acute organophosphorus nerve agent and pesticide exposure and therapeutic evaluation," Toxics, vol. 8, p. 106, 2020.

[20] F. Wang, W. Guan, L. Xu et al., "Effects of nanoparticles on algae: adsorption, distribution, ecotoxicity and fate," Applied Sciences, vol. 9, no. 8, Article ID 1534, 2019.

[21] C. Jin, C. Jin, X. Siyu et al., "Alginate/chitosan microcapsules for in-situ delivery of the protein, interleukin-1 receptor antagonist (IL-1Ra), for the treatment of dextran sulfate sodium (DSS)-induced colitis in a mouse model," European Journal of Pharmaceutics and Biopharmaceutics, vol. 137, pp. 112-121, 2019.

[22] P. Bhattarai, M. I. Cosacak, V. Mashkaryan et al., "Neuronglia interaction through Serotonin-BDNF-NGFR axis enables regenerative neurogenesis in Alzheimer's model of adult 
zebrafish brain," PLoS Biology, vol. 18, no. 1, Article ID e3000585, 2020.

[23] T. Grade, P. Campbell, T. Cooley et al., "Lead poisoning from ingestion of fishing gear: a review," Ambio, vol. 48, pp. 1023-1038, 2019.

[24] R. E. Green and D. J. Pain, "Risks to human health from ammunition-derived lead in Europe," Ambio, vol. 48, pp. 954-968, 2019.

[25] W. Mahmood, H. Saleem, I. Ahmad et al., "In-vitro studies on acetylcholinesterase and butyrylcholinesterase inhibitory potentials of aerial parts of Vernonia oligocephala (Asteraceae)," Tropical Journal of Pharmaceutical Research, vol. 17, pp. 2445-2448, 2018.

[26] Q. Guo, H. Cao, X. Qi et al., "Research progress in reversal of tumor multi-drug resistance via natural products," Anticancer Agents in Medicinal Chemistry, vol. 17, pp. 1466-1476, 2017.

[27] L. Liu, P. Liu, Z. Liang et al., "Poly (ADP-ribose) polymerase inhibitors combined with other small-molecular compounds for the treatment of ovarian cancer," Anti-Cancer Drugs, vol. 30, no. 6, pp. 554-561, 2019.

[28] M. A. Handley, K. Nelson, E. Sanford et al., "Examining lead exposures in California through state-issued health alerts for food contamination and an exposure-based candy testing program," Environmental Health Perspectives, vol. 125, no. 10, Article ID 104503, 2017.

[29] J. C. Cline, "Nutritional aspects of detoxification in clinical practice," Alternative Therapies in Health and Medicine, vol. 21, pp. 54-62, 2015.

[30] Y. Li, H. Lv, C. Xue, N. Dong, C. Bi, and A. Shan, "Plant polyphenols: potential antidotes for lead exposure," Biological Trace Element Research, 2020.

[31] A. Nakatani, X. Li, J. Miyamoto et al., "Dietary mung bean protein reduces high-fat diet-induced weight gain by modulating host bile acid metabolism in a gut microbiota-dependent manner," Biochemical and Biophysical Research Communications, vol. 501, pp. 955-961, 2018.

[32] Y. Yao, Y. Zhu, and G. Ren, "Immunoregulatory activities of polysaccharides from mung bean," Carbohydrate Polymers, vol. 139, pp. 61-66, 2016.

[33] J. Xie, M. Du, M. Shen et al., "Physico-chemical properties, antioxidant activities and angiotensin-I converting enzyme inhibitory of protein hydrolysates from Mung bean (Vigna radiate)," Food Chemistry, vol. 270, pp. 243-250, 2019.

[34] J. Geng, W. Liu, J. Gao et al., "Andrographolide alleviates Parkinsonism in MPTP-PD mice via targeting mitochondrial fission mediated by dynamin-related protein 1," British Journal of Pharmacology, vol. 176, pp. 4574-4591, 2019.

[35] P. Chen, X. Piao, and P. Bonaldo, "Role of macrophages in Wallerian degeneration and axonal regeneration after peripheral nerve injury," Acta Neuropathologica, vol. 130, no. 5, pp. 605-618, 2015.

[36] D. Grinsell and C. P. Keating, "Peripheral nerve reconstruction after injury: a review of clinical and experimental therapies," BioMed Research International, vol. 2014, Article ID 698256, 13 pages, 2014.

[37] R. Sullivan, T. Dailey, K. Duncan, N. Abel, and C. Borlongan, "Peripheral nerve injury: stem cell therapy and peripheral nerve transfer," International Journal of Molecular Sciences, vol. 17, no. 12, p. 2101, 2016.

[38] A. Faroni, S. A. Mobasseri, P. J. Kingham et al., "Peripheral nerve regeneration: experimental strategies and future perspectives," Advanced Drug Delivery Reviews, vol. 83, pp. 160-167, 2015.
[39] M. L. Wang, M. Rivlin, J. G. Graham et al., "Peripheral nerve injury, scarring, and recovery," Connective Tissue Research, vol. 60, pp. 3-9, 2019.

[40] T. Gordon and A. W. English, "Strategies to promote peripheral nerve regeneration: electrical stimulation and/or exercise," European Journal of Neuroscience, vol. 43, pp. 336-350, 2016.

[41] B. Liu, W. Xin, J.-R. Tan et al., "Myelin sheath structure and regeneration in peripheral nerve injury repair," Proceedings of the National Academy of Sciences of the United States of America, vol. 116, pp. 22347-11352, 2019. 